\title{
Leaf morphological and genetic variation between Quercus rubra and Quercus ellipsoidalis: compa- rison of sympatric and parapatric populations
}

\author{
O. Gailing, S. Kostick, O. Caré, S. Khodwekar
}

Gailing O., Kostick S., Caré O., Khodwekar S., 2018. Leaf morphological and genetic variation between Quercus rubra and Quercus ellipsoidalis: comparison of sympatric and parapatric populations. Ann. For. Res. 61(1): 81-94.

Abstract. Species boundaries in oaks are often not clear-cut, which is potentially a result of interspecific hybridization with trait introgression and phenotypic plasticity. Quercus rubra L. and Quercus ellipsoidalis E.J. Hill are two interfertile partially sympatric red oak species (section Lobatae) with different adaptations to drought. Quercus ellipsoidalis is the most drought tolerant of the North American red oak species and is characterized by deep tap roots, a shrubby growth and by deeply dissected leaves. Genetic differentiation between species is low for most molecular markers. However, one genic microsatellite in a CONSTANS-like (COL) gene, FIR013, was previously identified as outlier locus under strong divergent selection between species. In this study, we analyzed leaf morphometric traits in neighboring (parapatric) $Q$. rubra/Q. ellipsoidalis populations and in one sympatric population from the same region along an environmental gradient. Using multivariate statistics of leaf traits both species showed distinct bimodal frequency distributions for the first canonical discriminant function with some overlap in the phenotypic extremes, especially in the sympatric population. Leaf dissection traits showed strong and consistent differentiation between species in sympatric and parapatric populations, while differentiation for leaf size was lower in the sympatric population under more similar environmental conditions. Leaf phenotypes in F1 hybrids and introgressive forms suggested maternal effects and introgression of leaf traits between species. The association of outlier gene copy number at FIR013 with species-discriminating leaf traits in Quercus rubra can be a reflection of population differences since outlier gene copy number and population membership show significant collinearity. Similar environmental selection pressures on outlier alleles and leaf shape could also have resulted in this association. In future studies, segregating full-sib families could be used to test whether outlier alleles and associated genomic regions are indeed associated with leaf traits or other species-discriminating characters.

Keywords leaf traits, EST-SSRs, oaks, hybridization

Authors. Oliver Gailing (ogailin@gwdg.de) - School of Forest Resources and Environmental Science, Michigan Technological University, Houghton, MI, 49931-1295, USA \& Forest Genetics and Forest Tree Breeding, Faculty of 
Forest Sciences, University of Göttingen, 37077 Göttingen, Germany; Sarah Kostick - Biological Sciences Department, Michigan Technological University, Houghton, MI, 49931-1295, USA \& Washington State University, Department of Horticulture, Pullman, WA; Oliver Caré - Forest Genetics and Forest Tree Breeding, Faculty of Forest Sciences, University of Göttingen, 37077 Göttingen, Germany; Sudhir Khodwekar - School of Forest Resources and Environmental Science, Michigan Technological University, Houghton, MI, 499311295, USA \& University of Mumbai, Mumbai, India.

Manuscript received May 15, 2018; revised June 19, 2018; accepted June 20, 2018; online first July 3, 2018.

\section{Introduction}

Oak species from the same taxonomic section frequently hybridize, but hybrids are mainly restricted to the contact zones between species (Curtu et al. 2007, de Heredia et al. 2009, Owusu et al. 2015). Phenotypic differentiation between closely related oaks is often not complete potentially as result of phenotypic plasticity (Bruschi et al. 2003) and introgression between species (Curtu et al. 2007). However, multivariate statistics of leaf traits previously showed a good separation between oak species even across the species distribution range of the two hybridizing white oak species Quercus robur L. and Quercus petraea (Matt.) Liebl. (Kremer et al. 2002). Similarly, evidence that this taxon complex remains distinct even on a small scale was provided by using spatially explicit, multivariate analyses of leaf morphological and nuclear microsatellite data conducted in a mixed oak stand of $Q$. petraea and $Q$. robur (Gugerli et al. 2007).

In closely related oak species with different ecological adaptations low interspecific genetic differentiation at most nuclear and anonymous DNA markers suggested interspecific gene flow (Mariette et al. 2002, Scotti-Saintagne et al. 2004, Lind-Riehl et al. 2014). In addition to low overall interspecific genetic differentiation, the absence of significant interspecific differentiation at maternally inherited chloroplast markers and sharing of locally restricted chloroplast haplotypes between species of the same taxonomic section was interpreted as 82 evidence for interspecific gene flow (Petit et al. 2003, Zhang et al. 2015). Likewise, paternity analysis in oaks of section Quercus and Lobatae revealed contemporary interspecific gene flow in neighboring geographically distinct (parapatric) and in sympatric populations (Curtu et al. 2009, Lepais et al. 2009, Moran et al. 2012, Khodwekar \& Gailing 2017). While low genetic differentiation alone can also be interpreted as shared ancestral variation (Muir \& Schlötterer 2005), the observation of contemporary interspecific gene flow and the sharing of rare and locally restricted chloroplast haplotypes in both European white oaks (section Quercus) and North American red oaks (section Lobatae) is clear evidence for interspecific gene flow between oak species (Lexer et al. 2006, Neophytou et al. 2011, Moran et al. 2012, Zhang et al. 2015). Yet, despite interspecific gene flow, hybridizing species with different adaptations to drought in both section Quercus and Lobatae are highly differentiated at some loci/genomic regions as a signature of strong divergent selection (Scotti-Saintagne et al. 2004, Lind-Riehl et al. 2014).

Here we focus on the two North American red oak species Quercus rubra L. and Quercus ellipsoidalis E.J. Hill with different adaptations to drought such as differences in leaf conductance, root depth and leaf shape (Abrams 1990, Jensen et al. 1993). Both species are also differentiated at leaf morphometric and acorn traits and are characterized by different growth forms (Burns \& Honkala 1990, Jensen et al. 1993). However, no single trait is diag- 
nostic for the species, only a combination of leaf morphometric traits is informative to assign most samples to genetically identified species (Gailing et al. 2012). Intermediate leaf morphologies between $Q$. rubra and $Q$. ellipsoidalis were interpreted as the result of interspecific hybridization and introgression (Jensen et al. 1993). However, genetic variation for species-discriminating leaf traits has also been found within species, e.g. for the European white oak species Quercus robur as revealed by QTL mapping in a $Q$. robur full-sib family (Saintagne et al. 2004, Gailing 2008). Furthermore, the expression of leaf traits is strongly affected by environmental conditions in both European white oaks and North American red oaks (Saintagne et al. 2004, Gailing 2008, Gailing et al. 2012, Gailing et al. 2013). In summary, multivariate analyses of leaf morphological traits are useful to differentiate between closely related species. However, individual traits show overlapping frequency distributions between species likely as result of a combination of factors: phenotypic plasticity, genetic variation in traits within species and interspecific introgression.

Quercus ellipsoidalis as the most drought tolerant of North American red oak species has small and deeply dissected leaves, while leaves are larger and less dissected in Q. rubra (Jensen et al. 1993). Deeply dissected and small leaves in $Q$. ellipsoidalis can be interpreted as an adaptation to dry and hot environments allowing for a more efficient transport of water (Sack \& Holbrook 2006, Nicotra et al. 2011) and a more rapid heat transfer (Gurevitch \& Schuepp 1990) than the larger and less dissected leaves of $Q$. rubra. To quantify these leaf morphological differences between species, a set of leaf morphometric traits has been developed and applied for species distinction using multivariate analyses (Jensen et al. 1993, Gailing et al. 2012).

For these two oak species, genetic marker analyses at non-genic nuclear microsatellites (nuclear Simple Sequence Repeats, nSSRs) and at genic EST-SSRs showed low interspecific differentiation for most markers (Lind \& Gailing 2013, Lind-Riehl et al. 2014). However, one EST-SSR, FIR013, was identified as outlier locus and showed highly elevated interspecific differentiation in parapatric $\left(\mathrm{F}_{\mathrm{ST}}=\right.$ 0.79 ) and in sympatric $Q$. rubra/Q. ellipsoidalis populations $\left(\mathrm{F}_{\mathrm{ST}}=0.64\right)$ from the same region as signature of strong divergent selection, likely driven by soil moisture, in the face of gene flow (Lind-Riehl et al. 2014, Khodwekar \& Gailing 2017, Lind-Riehl \& Gailing 2017). The variable trinucleotide SSR was located in the coding region of a CONSTANS-like $(C O L)$ gene and coded for a poly-Q repeat motif (Lind-Riehl \& Gailing 2017). While both species were not completely fixed on alternative alleles, $Q$. ellipsoidalis trees were generally characterized by a one repeat unit shorter poly-Q repeat than $Q$. rubra trees (138 bp in $Q$. ellipsoidalis, 141 bp in Q. rubra) (Lind-Riehl \& Gailing 2017). COL genes were associated with flowering time and growth in other species (Herrmann et al. 2010, Hsu et al. 2012). In $Q$. petraea the same $C O L$ gene was associated with the timing of vegetative bud burst (Alberto et al. 2013) which is directly related to flowering time in oaks (Chesnoiu et al. 2009, Collins et al. 2015). In the here investigated sympatric $Q$. rubra/Q. ellipsoidalis population in the Baraga Plains region, gene copy numbers of the Q. rubra-typical outlier allele 141 in $Q$. ellipsoidalis and of the Q. ellipsoidalis-typical outlier allele 138 in Q. rubra were associated with soil quality as defined by water holding capacity and nutrient availability (Khodwekar \& Gailing 2017).

In this study we evaluated species differentiation at leaf traits by analyzing leaf morphometric traits in one sympatric and in four parapatric Q. rubra/Q. ellipsoidalis populations. Our specific objectives are to compare interspecific differentiation at leaf traits between sympatric and parapatric stands and evaluate their utility for species discrimination, to analyze the association between species as derived from genet- 
ic assignment analysis and leaf traits, to evaluate introgression of leaf traits between species and to assess the association of outlier alleles, soil humidity and population membership with leaf traits in each species.

We hypothesize that differences in leaf dissection and size as potential adaptations to drought (Nicotra et al. 2011) are (1) maintained between species in sympatric populations even under similar environmental conditions and (2) associated with soil moisture and outlier allele copy number which could reflect correlated environmental selection.

\section{Materials and methods}

\section{Study sites}

Two to three sun leaves per tree were collected for 96 adult trees from one sympatric Q. rubra/Q. ellipsoidalis stand (FC-S) in the Baraga Plains region on the Upper Peninsula of Michigan for leaf measurements and DNA extraction. Additionally, leaves from 185 adult trees from parapatric populations of the same region were included, two $Q$. rubra popula- tions (FC-A: 44 samples, FC-B: 50 samples) and two Q. ellipsoidalis populations (FC-C: 32 samples, FC-E: 59 samples). In the sympatric population, individuals of both species occurred next to each other on Rubicon sand, while $Q$. ellipsoidalis was absent on adjacent soils with higher water holding capacity (Khodwekar \& Gailing 2017). In parapatric populations, Q. rubra and Q. ellipsoidalis were several kilometers apart from each other (3.2 $\mathrm{km}$ to $8.8 \mathrm{~km}$ ) (Lind-Riehl et al. 2014). The location and site description of the investigated populations are presented in Table 1. For the parapatric populations leaf traits have already been characterized (Gailing et al. 2012) (Table 1).

\section{Leaf measurements}

For each tree of the sympatric stand the largest and fully developed leaf was measured. For the parapatric stands, mean values per tree were derived from the measurement of the four largest leaves per tree as described in Gailing et al. (2012). The leaf morphometric traits were measured as described in Jensen et al. (1993) and Gailing et al. (2012). Specifically, we mea-

Table 1 Sympatric and parapatric Quercus rubra / Q. ellipsoidalis populations

\begin{tabular}{|c|c|c|c|c|c|c|}
\hline $\begin{array}{l}\text { Abbre- } \\
\text { viation }\end{array}$ & Species & $\begin{array}{l}\text { Sample } \\
\text { size (n) }\end{array}$ & Soil characteristics & Latitude & Longitude & $\begin{array}{l}\text { Mean } \\
\text { altitude } \\
(\mathrm{m})\end{array}$ \\
\hline \multirow{2}{*}{ FC-S } & Q. rubra & \multirow{2}{*}{96} & $\begin{array}{l}\text { 3: Keweenaw-Kalkaska } \\
\text { Complex }\end{array}$ & $46^{\circ} 40^{\prime} 27^{\prime \prime} \mathrm{N}$ & $88^{\circ} 32^{\prime} 06^{\prime \prime} \mathrm{W}$ & 393 \\
\hline & $\begin{array}{l}\text { Q. rubra / } \\
\text { Q. ellipsoidalis }\end{array}$ & & 2: Rubicon sand & $45^{\circ} 50^{\prime} 01^{\prime \prime} \mathrm{N}$ & $88^{\circ} 32^{\prime} 04^{\prime \prime} \mathrm{W}$ & 393 \\
\hline FC-A & Q. rubra & 44 & $\begin{array}{l}\text { 3: Keweenaw-Kalkaska } \\
\text { Complex }\end{array}$ & $46^{\circ} 39^{\prime} 09^{\prime \prime} \mathrm{N}$ & $88^{\circ} 36^{\prime} 06^{\prime \prime} \mathrm{W}$ & 297 \\
\hline FC-B & Q. rubra & 50 & $\begin{array}{l}\text { 4: Munising-Yalmer } \\
\text { loamy sand }\end{array}$ & $46^{\circ} 40^{\prime} 27^{\prime \prime} \mathrm{N}$ & $88^{\circ} 31^{\prime} 27^{\prime \prime} \mathrm{W}$ & 423 \\
\hline FC-C & Q. ellipsoidalis & 32 & 1: Grayling sand & $46^{\circ} 39^{\prime} 14^{\prime \prime} \mathrm{N}$ & $88^{\circ} 35^{\prime} 25^{\prime \prime} \mathrm{W}$ & 394 \\
\hline FC-E & Q. ellipsoidalis & 59 & 1: Grayling sand & $46^{\circ} 39^{\prime} 55^{\prime \prime} \mathrm{N}$ & $88^{\circ} 33^{\prime} 19^{\prime \prime} \mathrm{W}$ & 398 \\
\hline
\end{tabular}

Note. Soil type was identified according to the Soil Survey Area, Natural Resource Conservation Services, United States Department of Agriculture at http://websoilsurvey.sc.egov.usda.gov/App/WebSoilSurvey.aspx (Information downloaded and plotted on maps as a layer on September 5, 2016) (wSs_SSA_MI013_soildb_MI_2003_[2015-0921]_Baraga county and wss_SSA_MI013_soildb_MI_2003_[2015-09-21]_Delta county) Soils are ranked from poor (1) to rich (4) based on water holding capacity, site index and soil composition ( $\%$ organic matter, $\%$ sand). 
sured leaf blade length (LBL), leaf blade width defined by the basal lobe pair (LBWB), by the middle lobe pair (LBWM), and by the apical lobe pair (LBWA), interval between the basal pair of sinuses (INTB), the middle pair of sinuses (INTM) and the apical pair of sinuses (INTA), interval between center vein intersections (CENTER) and apical vein intersections (APEX) (Table 1 and Figure 1 - Supporting Information).

\section{Data analyses}

Significant differences in trait mean values between genetically identified species after exclusion of hybrids and introgressive forms were tested with an independent t-test in WINSTAT (Fitch 2006).

Factor analysis was performed in WINSTAT (Fitch 2006) to find the independent factors underlying the leaf traits and to visualize differences between genetically identified species. After Kaiser normalization we applied varimax normal rotation to the factor loadings to ensure that variables with large communalities have greater weight. Initial communalities were assumed to be equal to the highest correlation coefficient. Factor extraction was continued until the calculated eigenvalue of the factor was greater than one. Leaf factor scores for the extracted factors instead of the original variables were used for the association analyses with soil moisture, population membership and outlier allele count (see below).

Discriminant analysis was performed in IBM SPSS version 23.0 (IBM 2015) using the genetically identified species as the grouping variable. Prior probabilities were assumed to be equal for the classification of samples based on the discriminant functions. Canonical discriminant functions were calculated to describe the relation between the grouping variable and the independent variables (leaf traits). The function with the highest eigenvalue that best predicted the grouping variable was used to visualize the frequency distributions of dis- criminant scores for both species and their discrimination. The canonical correlation value was derived from the eigenvalue. The test statistics Wilk's Lambda was applied to test the dependency of the grouping variable and the independent variables. Standardized coefficients of the discriminant function were calculated to evaluate the importance of a given independent variable for the discriminant function. Finally, the discriminant function was used to classify all samples to species. The results were compared to the species identity as determined by genetic assignment analysis.

\section{Genetic assignment analysis}

Genetic assignment analysis in STRUCTURE (Pritchard et al. 2000) using a set of 16 informative microsatellites (5 nSSRs, 11 ESTSSRs) was performed for all samples and populations in earlier studies (Lind \& Gailing 2013, Lind-Riehl et al. 2014, Khodwekar \& Gailing 2017). Additionally, data on outlier locus FIR013 (Lind-Riehl et al. 2014, Khodwekar \& Gailing 2017) were used to evaluate introgression of species-typical outlier alleles between species and their association with leaf traits in both species. Genetic assignment analysis (without outlier locus FIR013) identified two genetic clusters corresponding to the species Q. rubra and Q. ellipsoidalis. Ancestry coefficients $(Q)$ were calculated for each sample $\left(Q_{\text {rubra }}+Q_{\text {ellipsoidalis }}=1\right)$. For comparability with other related studies (Curtu et al. 2007, Lind \& Gailing 2013, Lind-Riehl et al. 2014, Collins et al. 2015), individuals with $Q_{\text {ellipsoidalis }}$ $\geq 0.9$ were classified as $Q$. ellipsoidalis, with $Q_{\text {ellipsoidalis }}$ between 0.61 and 0.89 as $Q$. ellipsoidalis-like introgressive forms, with $Q_{\text {ellipsoidalis }}$ between 0.4 and 0.6 as $\mathrm{F}_{1}$ hybrids, with $Q_{\text {ellip- }}$ soidalis between 0.39 and 0.11 as Q. rubra-like introgressive forms and with $Q_{\text {ellipsoidalis }} \leq 0.1$ as Q. rubra.

\section{Correlation of species ancestry with leaf traits}


Spearman rank correlation coefficients between $Q$. ellipsoidalis ancestry and leaf traits and one-sided significances were calculated in WINSTAT (Fitch 2006) for sympatric, parapatric and all populations combined.

\section{Association of introgressed outlier alleles at FIR013 with leaf factor scores in each species}

Genotypes at outlier locus FIR013 were translated into the number of 138 or 141 alleles (e.g. $0,1,2$ copies of allele 138 correspond to genotypes $141 / 141,138 / 141,138 / 138$ ) for genetically assigned $Q$. rubra and $Q$. ellipsoidalis trees. Based on data on water holding capacity (amount of water content), soil composition ( $\%$ sand, $\%$ organic matter) and $\mathrm{pH}$ from the USDA soil survey (http://websoilsurvey. sc.egov.usda.gov/App/WebSoilSurvey.aspx) we grouped soil from dry to moist (1: Grayling sand, 2: Rubicon sand, 3: Keweenaw-Kalkaska complex, 4: Munising- Yalmer loamy sand). Linear models were used to test for the association of soil moisture, population membership and outlier allele count with leaf factor scores (Bates et al. 2015). To reduce issues with multiple testing and to remove the redundancy among leaf traits we used the orthogonal factors of the factor analysis in linear models. Data were tested for normal distribution using Q-Q plots in the program RStudio (Team 2015). Generalized variance-inflation factors (GVIFs) were calculated to test for collinearity between variables with the package 'car' (Fox \& Weisberg 2011) leading to the removal of the population identity from the models, due to strong collinearity with soil moisture levels. For $Q$. ellipsoidalis only one observation of soil moisture level 4 was available and further, only one $Q$. rubra individual had two copies of allele 138 thus both were dropped from the models. Model selection by AIC was performed with the package 'MASS' (Venables \& Ripley 2002), with the null model (factor score $\sim 1$ ) and the most complex model (factor score $\sim$ allele count $*$ humidity level). Selected models were assessed for significant pairwise differences by Tukey HSD test in cases of single fixed effects and with simultaneous general linear hypothesis testing with 'multcomp' (Hothorn et al. 2008) in case of unbalanced models with two fixed effects (Bates et al. 2015, Team 2015).

\section{Results}

\section{Species differentiation}

Significant differences in trait mean values were determined for genetically assigned species for parapatric and sympatric populations and for all populations combined (Table 2). Generally, trait differences between species were less pronounced in the sympatric population where both species grow under more similar environmental/edaphic conditions than in parapatric populations for which the contrast in edaphic conditions is more pronounced. For example, in the sympatric population both species occur next to each other on Rubicon sand, while $Q$. ellipsoidalis is absent on the neighboring Keweenaw-Kalkaska complex with higher water holding capacity (see Table 1 and Khodwekar \& Gailing 2017). Especially leaf length (LBL) and leaf width characters (LBWB, LBWM, LBWA) were significantly higher in $Q$. rubra than in Q. ellipsoidalis in parapatric stands, but these interspecific differences were much less pronounced in sympatric stands with non-significant differentiation for LBWB and LBWM. Measurements of the intervals between leaf sinuses (INTA, INTB, INTM) as indicator of leaf dissection also showed less pronounced interspecific differences in sympatric stands, but the differentiation remained highly significant.

\section{Factor analysis}

Two factors were extracted that explained 


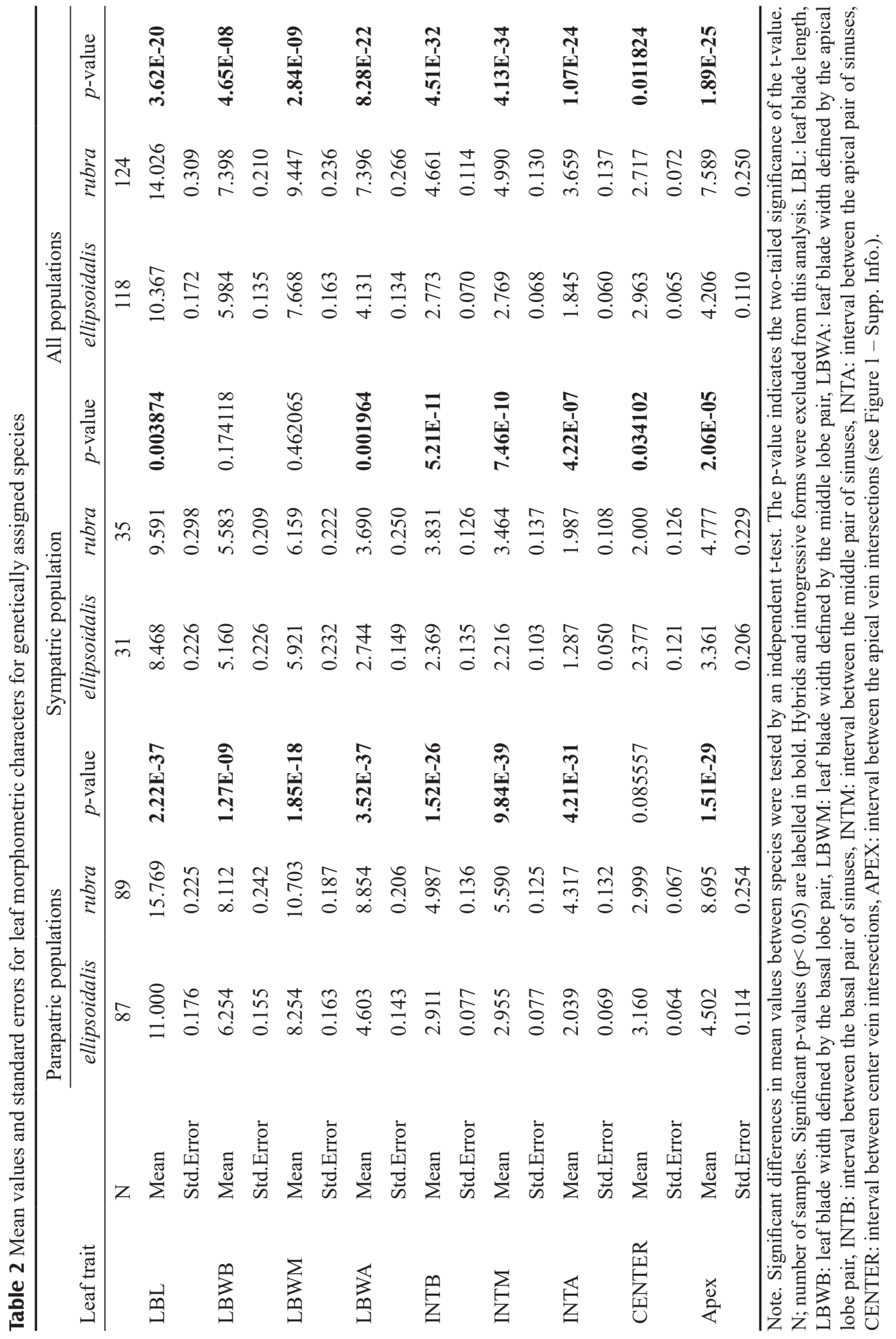


most of the phenotypic variance in sympatric (F1: 52.51\%, F2: 19.04\%), in parapatric (F1: $62.8 \%, \mathrm{~F} 2: 19.55 \%$ ), and in all populations combined (F1: $67.11 \%$, F2: 14.48\%). Factor loadings and communalities and correlations between factor scores and leaf traits are shown in Tables 2-3 - Supp. Info.. In the sympatric population where both species grow on the same soil type (Rubicon sand) factor score 1 is mainly correlated with leaf dissection characters INTB $(r=0.74)$, INTM $(r=0.87)$, INTA ( $\mathrm{r}$ $=0.90)$ and with Apex $(\mathrm{r}=0.80)$, while factor score 2 is mainly correlated with leaf length (LBL, $r=0.72$ ), leaf width defined by the middle and basal lobe pair (LBWM, LBWB; $r=$ 0.76, $r=0.80)$, and with CENTER $(r=0.85)$. Genetically identified species were separated along factor axis 1 (Figures 2-4 - Supp. Info.). In parapatric populations $\mathrm{F}_{1}$ hybrids group with $Q$. ellipsoidalis in the $Q$. ellipsoidalis stands FC-C and FC-E, while no $\mathrm{F}_{1}$ hybrids were found in Q. rubra stands. In the sympatric stand FC-S, one of the two $\mathrm{F}_{1}$ hybrids grouped with $Q$. ellipsoidalis, the other with $Q$. rubra (Figures 1-2, Supp. Info.). When both sympatric and parapatric populations are combined the separation between species along axis 1 is less prominent. In the sympatric stand, introgressive forms generally do not group consistently to morphological species along factor axis 1 . For example, one $Q$. ellipsoidalis-like introgressive form shows the highest score for factor 1 and groups with Q. rubra (FR86, Figures 1-2 - Supp. Info.).

\section{Discriminant analysis}

The frequency distributions of discriminant scores for canonical discriminant function 1 were separated between genetically identified species with some overlap for sympatric, parapatric and for all populations (Figures 1-2; and Figure 5 - Supp. Info.). The overlap was more pronounced for sympatric than for parapatric populations. Consequently, a higher discrimination between species was found for para- patric (Canonical correlation: 0.880, Wilks' Lambda: $0.225, \mathrm{p}<0.0001)$ than for sympatric populations (Canonical correlation: 0.817, Wilks' Lambda: 0.33, p $<0.0001$ ). The interval between the basal pair of sinuses (INTB) had the highest absolute standardized scoring coefficient for sympatric (1.0895), parapatric $(0.81145)$ and for all populations (1.1498).

\section{Trait correlations with species ancestry}

Ancestry coefficients $(Q)$ for each sample $\left(Q_{r u-}\right.$ ${ }_{\text {bra }}+Q_{\text {ellipsoidalis }}=1$ ) were derived from genetic assignment analysis. Here, we correlated $Q$. ellipsoidalis ancestry (0 to 1, 0: Q. rubra, 1: Q. ellipsoidalis) with leaf traits (Supplementary Table 4). In parapatric populations, Q. ellipsoidalis ancestry showed highly significant correlations with leaf length/leaf width characters (LBL, LBWB, LBWM, LBWA), leaf dissection (INTA, INTB, INTM) and the interval between apical vein intersections (APEX). In sympatric populations, high and negative correlations with ancestry $(\mathrm{r}<-0.5)$ were only found for leaf dissection traits INTA, INTB and INTM. Correlations between $Q$. ellipsoidalis ancestry and LBWB and LBWM were not significant. For sympatric, parapatric and all populations, leaf factor score 1 showed a high correlation with $Q$. ellipsoidalis ancestry $(\mathrm{r}=-0.60, \mathrm{r}=-0.72, \mathrm{r}=-0.66)$, while factor score 2 revealed no significant association.

\section{Associations of outlier alleles at $\mathrm{COL}$ with leaf traits}

Allele 138 in Q. rubra showed a significant negative correlation with all leaf traits as well as with factor 1 and 2 of the factor analysis across all populations, while allele 141 in $Q$. ellipsoidalis was not correlated with any leaf trait. To reduce issues with multiple testing and to remove the redundancy among traits we used the orthogonal factors of the factor analysis in linear models to test for the association between leaf shape, the outlier allele count (al- 

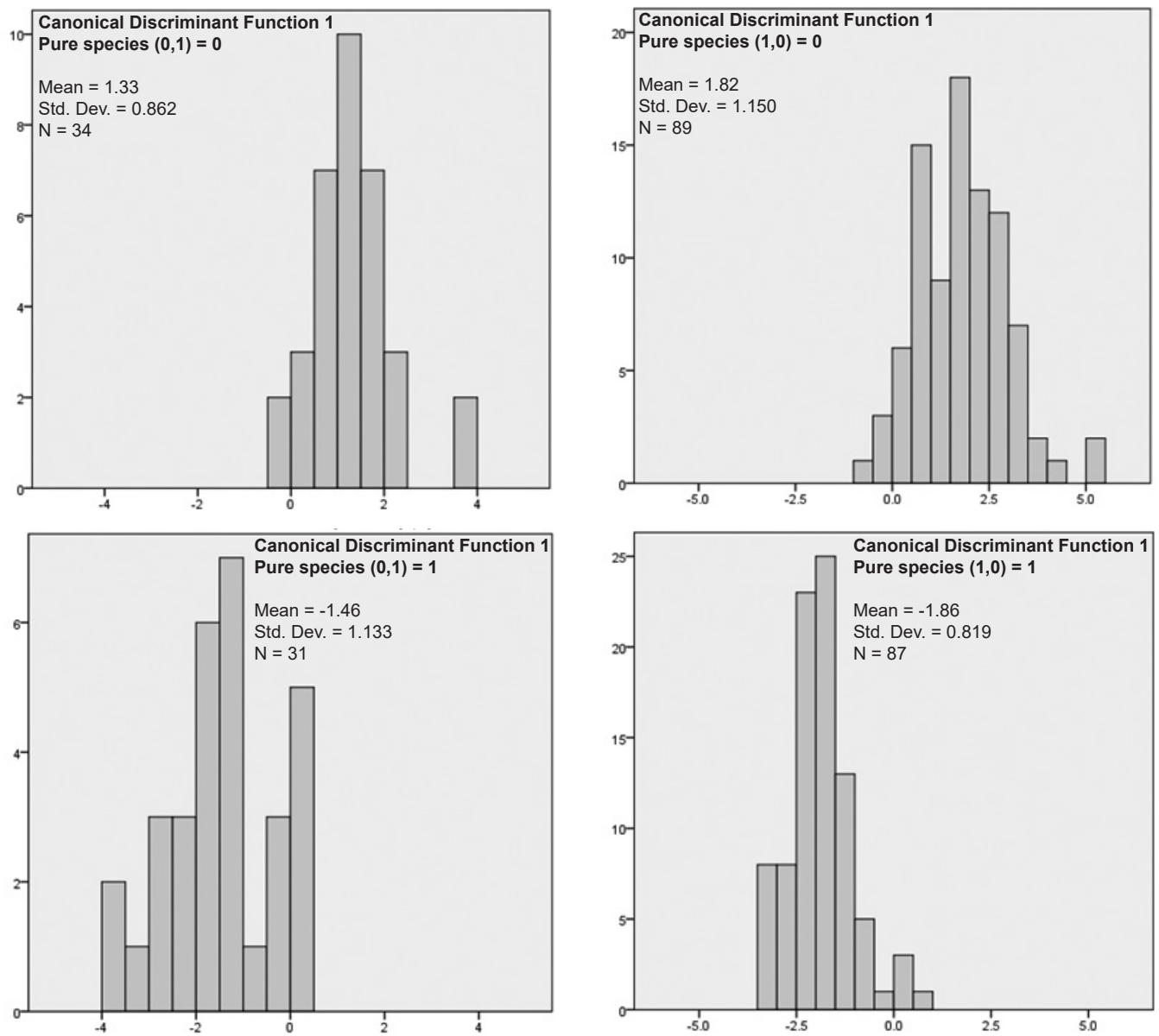

Figure 1 Distribution of discriminant scores in genetically assigned $Q$. rubra (top) and $Q$. ellipsoidalis (bottom) individuals in the sympatric population FC-S

lele 138 in Q. rubra) and soil moisture.

In the species $Q$. ellipsoidalis no significant influence of the allele counts on both leaf factor scores could be detected, as well as no improvement of the model fit by including this fixed effect was observed. Soil moisture is a significant explanatory variable in both cases and as final model factor score $\sim$ humidity level was considered. Differences in leaf factor scores and corresponding $\mathrm{p}$-values are given in Table 3.

Both best models for Q. rubra included the

Figure 2 Distribution of discriminant scores in genetically assigned $Q$. rubra (top) and $Q$. ellipsoidalis (bottom) individuals in the parapatric population FC-S

allele count and the soil moisture level without interaction (Table 4). No correlation between these two fixed terms could be detected (GVIF 1.038 and 1.009). The linear model for leaf factor score 1 indicated a significant influence of both fixed effects, as for factor score 2 only soil moisture was significant. For leaf factor 2, allele count was not significant but considerably improved the model fit and was therefore included in the model. In the multiple comparison testing displayed in Table 4 significant differences in leaf factor score 1 
Table 3 Pairwise comparisons of leaf factor score values between soil moisture levels for the final models in Q. ellipsoidalis

\begin{tabular}{lllll}
\hline Comparison & \multicolumn{2}{l}{ Factor score 1, Q. elllipsoidalis } & \multicolumn{2}{l}{ Factor score 2, Q. ellipsoidalis } \\
\hline Soil moisture level & Mean difference & $p$-value & Mean difference & $p$-value \\
\hline $2-1$ & -0.287 & 0.001 & -0.959 & 0.000 \\
$3-1$ & 0.211 & 0.358 & -1.455 & 0.000 \\
$3-2$ & 0.498 & 0.007 & -0.496 & 0.279 \\
\hline
\end{tabular}

Table 4 Pairwise comparisons of leaf factor score values between soil moisture levels and outlier allele counts for the final models in Q. rubra

\begin{tabular}{lllll}
\hline Comparison & Factor score 1, Q. rubra & \multicolumn{3}{l}{ Factor score 2, Q. rubra } \\
\hline $\begin{array}{l}\text { Soil moisture } \\
\text { level }\end{array}$ & $\begin{array}{l}\text { Average marginal } \\
\text { mean difference }\end{array}$ & $p$-value & $\begin{array}{l}\text { Average marginal } \\
\text { mean difference }\end{array}$ & $p$-value \\
\hline $3-2$ & 0.07 & 0.73 & -0.62 & 0.12 \\
$4-2$ & -1.05 & 0.02 & -0.47 & 0.43 \\
$4-3$ & -1.12 & 0.02 & 0.15 & 0.82 \\
Allele count & & & & 0.20 \\
$1-0$ & -0.93 & 0.00 & -0.59 & \\
\hline
\end{tabular}

Note. Allele count: 0 or 1 copy of outlier allele 138 .

were detected between humidity levels (4-2, 4-3) and allele count (zero versus one copy of allele 138). After adjusting the p-value for multiple pairwise testing no significant differences were found between levels of fixed effects and factor score 2 .

\section{Discussion}

Leaf traits are often used to differentiate between closely related species in oaks (Jensen et al. 1993, Kremer et al. 2002). However, their expression is characterized by a plastic response to environmental/light conditions (Gonzalez-Rodriguez \& Oyama 2005) which might obscure species boundaries. In this study, mean values of most leaf traits (with the exception of CENTER) showed highly significant differences between species in parapatric populations where both species grow on different soil types with regard to water holding capacity and nutrient availability. Specifically, Q. ellipsoidalis which occurs preferentially on dry soils is characterized by much smaller and more deeply dissected leaves than $Q$. ru- bra (Jensen et al. 1993, Gailing et al. 2012). In the sympatric population where both species occur on intermediate soil types (in the transition zone between Keweenaw-Kalkaska complex and Rubicon sand) under more similar environmental conditions, differences in leaf size (leaf length and width) are much less pronounced and non-significant at the $1 \%$ level. Thus, leaf size is strongly influenced by environmental/soil conditions and interspecific differences are emphasized in parapatric populations which grow on different soils. Also, introgression and hybridization between species contributes to high variation in leaf traits in natural populations (Cottam et al. 1982). However, introgressive forms and hybrids were excluded from the calculation of interspecific differentiation in the present study. In contrast to leaf size characters, interspecific differences in mean values for intervals between pairs of sinuses along the leaf as indicator for leaf dissection remained highly significant in sympatric populations. Differences between species at these traits reflect to a larger degree genetic differences and are useful to distinguish both species in sympatry 
where environmental contrasts are weaker. Accordingly, in sympatric populations we found high correlations between species ancestry and leaf dissection (INTA, INTB, INTM), but not with leaf size traits. Overlapping frequency distributions for individual traits and for the discriminant scores are due to high variation in leaf traits within species and phenotypic plasticity (Kremer et al. 2002). The grouping of putative $\mathrm{F}_{1}$ hybrids with both Q. rubra and Q. ellipsoidalis in the factor analysis may be a reflection of maternal effects. Thus, in oaks $\mathrm{F}_{1}$ hybrids are frequently similar to the maternal parent (Cottam et al. 1982, Kleinschmit et al. 1995, Kremer et al. 2002). The inconsistent grouping of introgressive forms to species and generally low separation along factor axis 1 may reflect introgression of leaf traits between species or higher phenotypic plasticity of introgressive forms. Typical Quercus rubra leaf characteristics and a $Q$. rubra-like growth form especially for one $Q$. ellipsoidalis-like introgressive form (FR086, Figure 1 - Supp. Info.) suggested that introgression of specific genomic regions could be associated with morphological species identity.

Leaf dissection has been described as an adaptation to hot and dry environments (Kramer and Boyer 1995, Nicotra et al. 2011). First, deeply dissected leaves have a decreased hydraulic resistance since the ratio of mesophyll tissue to conductive veins is decreased (Sack $\&$ Holbrook 2006). Second, deeply dissected leaves allow for a more rapid heat transfer than entire leaves, but they are also prone to more rapid water vapor loss because of thinner boundary layers (Gurevitch \& Schuepp 1990, Kramer \& Boyer 1995). In the present study leaf factor score 1 which is associated with differences in leaf dissection between $Q$. ellipsoidalis and $Q$. rubra was associated with soil quality along a soil water / nutrient gradient. While leaf dissection and the associated reduction in leaf area may be an adaptation to hot and sunny environments, leaf dissection was not associated with environmental conditions in other species (Nicotra et al. 2011). Thus, growth and survival in seasonally dry environments is likely related to leaf dissection, but is also dependent on a combination of other physiological traits.

\section{Outlier allele copy number and soil mois- ture show a significant association with leaf shape}

Outlier locus $C O L$ showed signatures of strong divergent selection between $Q$. rubra and $Q$. ellipsoidalis. Quercus rubra was nearly fixed on allele 141 and $Q$. ellipsoidalis was nearly fixed on allele 138 (Lind-Riehl et al. 2014). An earlier study of the same sympatric population suggested that introgression of outlier alleles at $C O L$ was affected by environmental selection (Khodwekar \& Gailing 2017). Thus, introgression of allele 138 into Q. rubra was significantly associated with the occurrence on poorer/drier soils in the sympatric populations FC-S. Likewise, introgression of allele 141 into $Q$. ellipsoidalis was significantly associated with the occurrence of this species on richer soils (Khodwekar \& Gailing 2017). Here, we found that gene copy number of allele 138 in Q. rubra was associated with leaf factor 1 (smaller and deeply dissected leaves) across all populations. However, the frequency of this allele was higher in the sympatric population as in the parapatric populations. In a linear model using both soil moisture and outlier allele count of allele 138 in Q. rubra both variables were significantly associated with leaf factor 1 . Since outlier allele count and soil moisture revealed no collinearity, soil moisture was included in the model as factor confirming the significant association between allele count and leaf factor 1 . However, due to the high collinearity between allele count and population identity these findings have to be interpreted cautiously. High correlation in the whole dataset is present between the variables soil moisture and population identity as well as allele count and population identity. As nearly 
no correlation between allele count and soil moisture was found across all populations, the fitted models are mathematically valid. On the other hand, some levels of these categorial variables have few observations and thus leading to a very unbalanced design with high weight of some observations which weaken the general interpretability. At least for the observed samples we cannot rule out a causal relationship between allele count and leaf shape or similar selection pressures on both outlier alleles and leaf shape. Common garden trials for different genotypes at COL (138/138, $138 / 141,141 / 141$ ) in each species and in segregating full-sib families could be established to test whether introgression of outlier alleles is associated with species differences such as leaf trait variation and to identify genomic regions that are associated with these traits.

\section{References}

Abrams M.D., 1990. Adaptations and responses to drought in Quercus species of North America. Tree Physiology 7:227-238. DOI: 10.1093/treephys/7.1-2-3-4.227

Alberto F.J., Derory J., Boury C., Frigerio J.M., Zimmermann N.E., Kremer A., 2013. Imprints of natural selection along environmental gradients in phenology-related genes of Quercus petraea. Genetics 195:495-512. DOI: 10.1534/genetics.113.153783

Bates D., Machler M., Bolker B.M., Walker S.C., 2015. Fitting linear mixed-effects models using lme4. Journal of Statistical Software 67:1-48. DOI: $10.18637 /$ jss. v067.i01

Bruschi P., Grossoni P., Bussotti F., 2003. Within- and among-tree variation in leaf morphology of Quercus petraea (Matt.) Liebl. natural populations. Trees-Structure and Function 17:164-172.

Burns R.M., Honkala B.H., 1990. Silvics of North America, Washington, DC.

Chesnoiu E.N., Șofletea N., Curtu A.L., Toader A., Radu R., Enescu M., 2009. Bud burst and flowering phenology in a mixed oak forest from Eastern Romania. Annals of Forest Research 52:199-206.

Collins E., Sullivan A.R. Gailing O., 2015. Limited effective gene flow between two interfertile red oak species. Trees-Structure and Function 29:1135-1148. DOI: 10.1007/s00468-015-1194-3

Cottam W.P., Tucker J.M., Santamour Jr. F.S., 1982. Oak hybridization at the University of Utah. State Arboretum of Utah, University of Utah.

Curtu A.L., Gailing O., Finkeldey R., 2007. Evidence for

92 hybridization and introgression within a species-rich oak (Quercus spp.) community. BMC Evolutionary Biology 7:218. DOI: 10.1186/1471-2148-7-218

Curtu A.L., Gailing O., Finkeldey R., 2009. Patterns of contemporary hybridization inferred from paternity analysis in a four-oak-species forest. BMC Evolutionary Biology 9:284. DOI: 10.1186/1471-2148-9-284

de Heredia U.L., Valbuena-Carabana M., Cordoba M., Gil L., 2009. Variation components in leaf morphology of recruits of two hybridising oaks $Q$. petraea (Matt.) Liebl. and $Q$. pyrenaica Willd. at small spatial scale. European Journal of Forest Research 128:543-554. DOI: 10.1007/s10342-009-0302-6

Fitch R., 2006. WinSTAT for Excel.

Fox J., Weisberg S., 2011. An R companion to applied regression. 2nd edition. SAGE Publications, Inc., California.

Gailing O., 2008. QTL analysis of leaf morphological characters in a Quercus robur full-sib family ( $Q$. robur $x$ Q. robur ssp. slavonica). Plant Biology 10:624-634. DOI: $10.1111 /$ j.1438-8677.2008.00063.X

Gailing O., Bodénès C., Finkeldey R., Kremer A., Plomion C., 2013. Genetic mapping of EST-derived Simple Sequence Repeats (EST-SSRs) to identify QTL for leaf morphological characters in a Quercus robur full-sib family. Tree Genetics \& Genomes 9:1361-1367. DOI: 10.1007/s11295-013-0633-9

Gailing O., Lind J., Lilleskov E.A., 2012. Leaf morphological and genetic differentiation between Quercus rubra L. and Q. elliposidalis E. J. Hill populations in contrasting environments. Plant Systematics and Evolution 298:1533-1545. DOI: 10.1007/s00606-012-0656-y

Gonzalez-Rodriguez A., Oyama K.E.N., 2005. Leaf morphometric variation in Quercus affinis and $Q$. laurina (Fagaceae), two hybridizing Mexican red oaks. Botanical Journal of the Linnean Society 147:427-435. DOI: 10.1111/j.1095-8339.2004.00394.x

Gugerli F., Walser J.-C., Dounavi K., Holderegger R., Finkeldey R., 2007. Coincidence of small-scale spatial discontinuities in leaf morphology and nuclear microsatellite variation of Quercus petraea and $Q$. robur in a mixed forest. Annals of Botany 99:713-722. DOI: 10.1093/aob/mcm006

Gurevitch J., Schuepp P.H., 1990. Boundary layer properties of highly dissected leaves: an investigation using an electrochemical fluid tunnel. Plant Cell and Environment 13:783-792. DOI: 10.1111/j.1365-3040.1990. tb01094.x

Herrmann D., Barre P., Santoni S., Julier B., 2010. Association of a CONSTANS-LIKE gene to flowering and height in autotetraploid alfalfa. Theoretical and Applied Genetics 121:865-876. DOI: 10.1007/s00122-0101356-z

Hothorn T., Bretz F., Westfall P., 2008. Simultaneous inference in general parametric models. Biometrical Journal 50:346-363. DOI: 10.1002/bimj.200810425

Hsu C.Y., Adams J.P., No K., Liang H.Y., Meilan R., Pechanova O., Barakat A., Carlson J.E., Page G.P., Yu- 
ceer C., 2012. Overexpression of Constans homologs $\mathrm{CO} 1$ and $\mathrm{CO} 2$ fails to alter normal reproductive onset and fall bud set in woody perennial poplar. Plos One 7:e45448. DOI: 10.1371/journal.pone.0045448

IBM. 2015. IBM SPSS Statistics for Windows IBM Corp., Armonk, NY.

Jensen R.J., Hokanson S.C., Isebrands J.G., Hancock J.F., 1993. Morphometric variation in oaks of the apostle islands in Wisconsin - evidence of hybridization between Quercus rubra and Q. ellipsoidalis (Fagaceae). American Journal of Botany 80:1358-1366. DOI: 10.1002/ j.1537-2197.1993.tb15375.x

Khodwekar S., Gailing O., 2017. Evidence for environment-dependent introgression of adaptive genes between two red oak species with different drought adaptations. American Journal of Botany 104:1088-1098. DOI: 10.3732/ajb.1700060

Kleinschmit J.R.G., Bacilieri R., Kremer A., and A. Roloff A., 1995. Comparison of morphological and genetic traits of pedunculate oak (Quercus robur L.) and sessile oak (Q. petraea (Matt.) Liebl.). Silvae Genetica 44:256269.

Kramer P.J., Boyer J.S., 1995. Water relations of plants and soils. Academic Press, San Diego.

Kremer A., Dupouey J.L, Deans J.D., Cottrell J., Csaik1 U., Finkeldey R., Espinel S., Jensen J., Kleinschmit J., Van Dam B., Ducousso A., Forrest I., Lopez de Heredia U., Lowe A.J., Tutkova M., Munro R.C., Steinhoff S., Badeau V., 2002. Leaf morphological differentiation between Quercus robur and Quercus petraea is stable across western European mixed oak stands. Annals of Forest Science 59:777-787. DOI: 10.1051/forest:2002065

Lepais O., Petit R.J, Guichoux E., Lavabre J.E., Alberto F., Kremer A., and S. Gerber S., 2009. Species relative abundance and direction of introgression in oaks. Molecular Ecology 18:2228-2242. DOI: 10.1111/j.1365294X.2009.04137.x

Lexer C., Kremer A., Petit R.J., 2006., Shared alleles in sympatric oaks: recurrent gene flow is a more parsimonious explanation than ancestral polymorphism. Molecular Ecology 15:2007-2012. DOI: 10.1111/j.1365294X.2006.02896.x

Lind-Riehl J., Gailing O., 2017. Adaptive variation and introgression of a CONSTANS-like gene in North American red oaks. Forests 8:3. DOI: 10.3390/f8010003

Lind-Riehl J.F., Sullivan A.R., Gailing O., 2014. Evidence for selection on a CONSTANS-like gene between two red oak species. Annals of Botany 113:967-975. DOI: 10.1093/aob/mcu019

Lind J., Gailing O., 2013. Genetic structure of Quercus rubra L. and $Q$. ellipsoidalis E. J. Hill populations at gene-based EST-SSR and nuclear SSR markers. Tree Genetics \& Genomes 9:707-722. DOI: 10.1007/ s11295-012-0586-4

Mariette S., Cottrell J., Csaikl U.M., Goikoechea P., König A.O., Lowe A.J., Van Dam B.C., Barreneche T., Bodenes C., Streiff R., Burg K., Groppe K., Munro R.C., Tabbener H., Kremer A., 2002. Comparison of levels of genetic diversity detected with AFLP and microsatellite markers within and among mixed $Q$. petraea (Matt.) Liebl. and $Q$. robur L. stands. Silvae Genetica 51: 72-79.

Moran E. V., Willis J., Clark J.S., 2012. Genetic evidence for hybridization in red oaks (Quercus sect. Lobatae, Fagaceae). American Journal of Botany 99:92-100. DOI: 10.3732 ajb. 1100023

Muir G., Schlötterer C., 2005. Evidence for shared ancestral polymorphism rather than recurrent gene flow at microsatellite loci differentiating two hybridising oaks (Quercus spp.). Molecular Ecology 14:549-561. DOI: 10.1111/j.1365-294X.2004.02418.x

Neophytou C., Dounavi A., Fink S., Aravanopoulos F.A., 2011. Interfertile oaks in an island environment: I. High nuclear genetic differentiation and high degree of chloroplast DNA sharing between $Q$. alnifolia and $Q$. coccifera in Cyprus. A multipopulation study. European Journal of Forest Research 130:543-555. DOI: 10.1007/ s10342-010-0442-8

Nicotra A.B., Leigh A., Boyce C.K., Jones C.S., Niklas K.J., Royer D.L., Tsukaya H., 2011. The evolution and functional significance of leaf shape in the angiosperms. Functional Plant Biology 38:535-552. DOI: 10.1071/ FP11057

Owusu S. A., Sullivan A.R., Weber J.A., Hipp A.L., Gailing O., 2015. Taxonomic relationships and gene flow in four North American Quercus species. Systematic Botany 40:510-521. DOI: 10.1600/036364415X688754

Petit R.J., Bodénès C., Ducousso A., Roussel G., Kremer A, 2003. Hybridization as a mechanism of invasion in oaks. New Phytologist 161:151-164. DOI: 10.1046/j.1469-8137.2003.00944.x

Pritchard J. K., Stephens M., Donnelly P., 2000. Inference of population structure using multilocus genotype data. Genetics 155:945-959.

Sack L., Holbrook N.M., 2006. Leaf hydraulics. Annual Review of Plant Biology 57:361-381. DOI: 10.1146/ annurev.arplant.56.032604.144141

Saintagne C., Bodenes C., Barreneche T., Pot D., Plomion C., Kremer A., 2004. Distribution of genomic regions differentiating oak species assessed by QTL detection. Heredity 92:20-30. DOI: 10.1038/sj.hdy.6800358

Scotti-Saintagne C., Mariette S., Porth I., Goicoechea P.G., Barreneche T., Bodénès C., Burg K., Kremer A., 2004. Genome scanning of interspecific differentiation between two closely related oak species (Quercus robur L. and Q. petraea (Matt.) Liebl.). Genetics 168:16151626. DOI: $10.1534 /$ genetics. 104.026849

Team R., 2015. RStudio: Integrated development for R. RStudio, Inc., Boston, MA.

Venables W.N., Ripley B.D., 2002. Modern Applied Statistics with S. 4th edition. Springer, New York. DOI: 10.1007/978-0-387-21706-2

Zhang R., Hipp A.L., Gailing O., 2015. Sharing of chloroplast haplotypes among red oak species suggests interspecific gene flow between neighboring populations. Botany 93:691-700. DOI: 10.1139/cjb-2014-0261 


\section{Supporting Information}

The online version of the article includes Supporting Information:

Supp. Info. Table 1. Leaf morphometric traits and landmarks

\section{Supp. Info. Table 2.}

Supp. Info. Table 3. Coorelation between leaf factor scores and individual leaf traits

Supp. Info. Table 4. Correlation of Quercus ellipsoidalis ancestry as determined by genetic assignment analysis with leaf morphometric characters

Supp. Info. Figure 1. Quercus ellipsoidalis-like introgressive form with $Q$. rubra leaf morphology (FR86) and F1 hybrids with $Q$. ellipsoidalis (FE44) and Q. rubra (FR26) leaf morphology. In contrast to other leaf samples in FR26 the left and right side of the leaf are asymmetric. Landmarks for morphological measurements are shown according to Jensen et al. (1993) (Supp. Info. Table 1).

Supp. Info. Figure 2. Factor analysis for all samples in the sympatric Q. rubra / Q. ellipsoidalis population.

Supp. Info. Figure 3. Factor analysis for all samples in the parapatric populations (Q. rubra: FC-A, FC-B, Q. ellipsoidalis: FC-C, FCE).

Supp. Info. Figure 4. Factor analysis for all samples in sympatric and parapatric populations.

Supp. Info. Figure 5. Distribution of discriminant scores in genetically assigned $Q$. rubra and $Q$. ellipsoidalis in sympatric and parapatric populations 